\title{
Characterization, in Vitro and in Vivo Evaluation of Naringenin-Hydroxypropyl- $\beta$-Cyclodextrin Inclusion for Pulmonary Delivery
}

\author{
Minyi Guan, Rui Shi, Yuying Zheng ${ }^{\circledR}$, Xuan Zeng ${ }^{\circledR}$, Weiyang Fan, Yonggang Wang and \\ Weiwei Su * \\ Guangdong Engineering \& Technology Research Center for Quality and Efficacy Reevaluation of Post-Market \\ Traditional Chinese Medicine, Guangdong Key Laboratory of Plant Resources, School of Life Sciences, \\ Sun Yat-sen University, No. 135, Xingang Xi Road, Guangzhou 510275, China; mandyguan723@163.com (M.G.); \\ ruishi900930@gmail.com (R.S.); vicky_0224@126.com (Y.Z.); zengx6@mail2.sysu.edu.cn (X.Z.); \\ fanwy5@mail2.sysu.edu.cn (W.F.); wangyg@mail.sysu.edu.cn (Y.W.) \\ * Correspondence: lsssww@126.com; Tel./Fax: +86-20-8411-2398
}

Received: 11 December 2019; Accepted: 23 January 2020; Published: 28 January 2020

\begin{abstract}
Naringenin, a flavonoid compound which exists abundantly in Citrus fruits, is proven to possess excellent antitussive and expectorant effects. However, the clinical applications of naringenin are restricted by its poor solubility and low local concentration by oral administration. The aim of the present study is to prepare a naringenin-hydroxypropyl- $\beta$-cyclodextrin (naringenin-HP $\beta C D$ ) inclusion as an inhalation solution for pulmonary delivery. The naringenin-HP $\beta C D$ inclusion was characterized by phase solubility study, XRD, differential scanning calorimetry (DSC), proton nuclear magnetic resonance $\left({ }^{1} \mathrm{HNMR}\right)$, and two-dimensional rotating frame Overhauser effect spectroscopy (2D ROESY). The in vitro permeability of the inclusion was evaluated on Calu-3 cells and the pharmacokinetic profile of pulmonary delivery was investigated in Sprague-Dawley (SD) rats. Based on the linear model of phase solubility study, the relationship between naringenin and HP $\beta C D$ was identified as $\mathrm{A}^{\mathrm{L}}$ type with a 1:1 stoichiometry. XRD, DSC, and NMR studies indicated that the entire naringenin molecule is encapsulated into the cavity of HP $\beta C D$. HP $\beta C D$ could increase the concentration of naringenin in the epithelium-lining fluid (ELF) of Calu-3 cells and act as a sustained release system for naringenin. The pharmacokinetic profile of naringenin-HP $\beta C D$ inclusion showed rapid response and higher local concentration by pulmonary delivery. In conclusion, pulmonary delivery of naringenin-HP $\beta C D$ inclusion is a promising formulation strategy, which could provide a new possibility for the clinical application of naringenin.
\end{abstract}

Keywords: naringenin; hydroxypropyl- $\beta$-cyclodextrin; pulmonary delivery; NMR; permeability; pharmacokinetic

\section{Introduction}

Naringenin (5,7,4'-trihydroxyflavanone, Figure 1a) is a flavanone found abundantly in Citrus fruits, such as grapefruits, oranges and pummelos, and it is also the active ingredient of many Chinese herbal medicines [1]. As a polyphenolic compound, naringenin possesses diverse pharmacological activities such as anti-oxidant, anti-inflammatory, anti-atherogenic, and hepatoprotective [2]. In recent years, naringenin and its glucoside have been proven to exhibited excellent expectorant and antitussive effects in various in vitro and in vivo models, indicating that naringenin is a promising drug for the treatment of respiratory diseases [3-11]. 
a<smiles>O=C1C[C@H](c2ccc(O)cc2)Oc2cc(O)cc(O)c21</smiles>

b

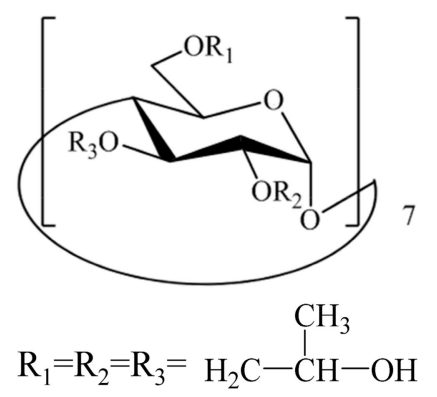

Figure 1. (a) The chemical structure of naringenin; (b) hydroxypropyl- $\beta$-cyclodextrin (HP $\beta C D)$.

Regretfully, the clinical applications of naringenin are limited by its poor solubility and bioavailability. A large number of formulation strategies were employed to solve these problems, including inclusion complexes, self-nanoemulsifying drug delivery system, solid dispersions, and nanoparticles [1,2,12-15]. However, these formulations were designed for oral administration, which has limited improvement of bioavailability due to the first pass effect, and tissue distribution study showed that most naringenin was concentrated in the gastrointestinal tract, while a little naringenin could reach the lungs [16-18]. Therefore, to achieve better therapeutic efficiency for respiratory diseases, it is necessary to develop a new delivery route for naringenin.

Benefits from the large surface area $\left(\sim 100 \mathrm{~m}^{2}\right)$ and the thin absorption membrane $(\sim 0.1-0.2$ $\mu \mathrm{m})$ of the lung, delivering drugs as an aerosol via pulmonary route allows rapid absorption, high local concentration, and systemic side-effect reduction of the drugs, which becomes a promising administration route in the treatment of respiratory diseases, such as asthma, chronic pulmonary infections, fibrosis or lung cancer [19]. It is noteworthy that prior to absorption, the drug should dissolve in the very thin pulmonary surface liquid [20], which is a challenge for naringenin due to its poor solubility and dissolution rate.

Cyclodextrins are cyclic oligosaccharides composed of covalently linked glucopyranose rings. They can provide a solution to increase the solubility of hydrophobic drugs by forming water-soluble inclusions, which encapsulate the entire or part of drugs in the hydrophobic cavities of cyclodextrins [21]. Hydroxypropyl- $\beta$-cyclodextrin (HP $\beta C D$ ) (Figure $1 b)$ is a chemically modified derivate of cyclodextrins with much higher solubility in water, and can be used safely as a complexing and solubilizing excipient in various administration routes of drugs. A number of studies reports on the applications of $\mathrm{HP} \beta C D$ solution for pulmonary delivery, in which the HP $\beta C D$ solution shows a compatible range of droplet size with pulmonary deposition, sustain-release characteristic in drug absorption, and non-toxic in short-term exposure [22-24].

In the present study, a naringenin-HP $\beta C D$ inclusion was prepared with the aim of increasing the solubility and local concentration of naringenin. The solubilizing ability and complexation efficiency of $\mathrm{HP} \beta C D$ with naringenin were demonstrated by the phase solubility study. The complexation mode of the inclusion was illustrated by nuclear magnetic resonance (NMR) studies. Calu-3 cells were employed as broncho-alveolar epithelial cell model to evaluate the in vitro performance of naringenin inclusion and the in vivo pharmacokinetic profile was investigated in SD rats.

\section{Results and Discussion}

\subsection{Phase Solubility Study}

The phase solubility diagram for naringenin in HP $\beta C D$ system is shown in Figure 2 . The solubility of naringenin increased linearly (37 to 273 times) as a function of HP $\beta C D$ concentration over the studied concentration range, which could be classified as $\mathrm{A}^{\mathrm{L}}$ type according to Higuchi and Connors [21]. The slope value was less than one, indicating the formation of a 1:1 stoichiometry inclusion between naringenin and HP $\beta C D$. The stability constant $\mathrm{K}_{\mathrm{s}}$ is introduced to present the solubilizing efficiency 
of cyclodextrins for a drug, and the complexation efficiency is used to describe the ratio between cyclodextrin inclusions and free cyclodextrins [25]. In this work, the $K_{\mathrm{s}}$ and complexation efficiency (CE) values were $2732.37\left(\mathrm{M}^{-1}\right)$ and 0.2732 , respectively. The molar ratio of naringenin to HP $\beta C D$ was about 1:5, suggesting that 1 out of every $5 \mathrm{HP} \beta C D$ molecules formed an inclusion with naringenin.

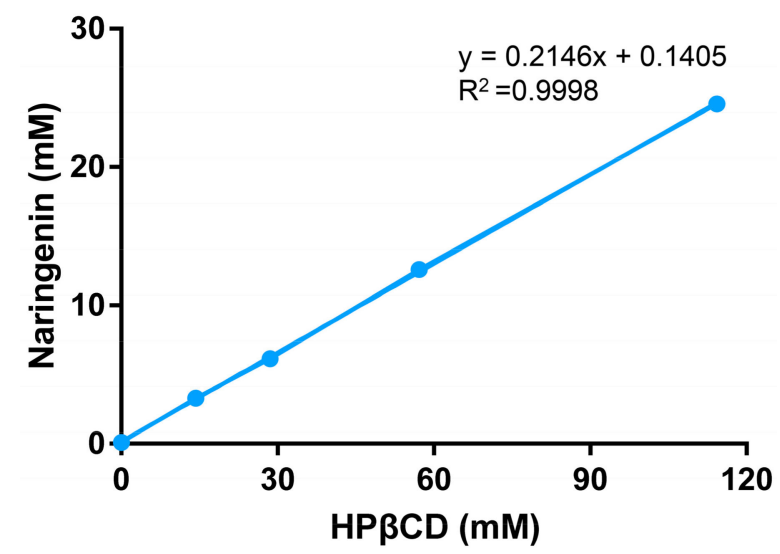

Figure 2. The phase solubility diagram of naringenin in the presence of $\mathrm{HP} \beta C D$ over a concentration range from 0 to $114.29 \mathrm{mM}$ (mean $\pm \mathrm{SD}, n=3$ ).

\subsection{Powder X-ray Diffraction (XRD)}

The XRD spectra of naringenin, $\mathrm{HP} \beta C D$, and their inclusion are shown in Figure 3. Naringenin exhibited its crystalline property with strongly sharp peaks in the range of $2 \theta$ from $3^{\circ}$ to $40^{\circ}$, while $\mathrm{HP} \beta C D$ displayed an amorphous property with no distinct peaks observed in the corresponding range. There was also no sharp peak shown in the XRD spectrum of naringenin-HP $\beta C D$ inclusion, suggesting that naringenin was encapsulated in $\mathrm{HP} \beta C D$.
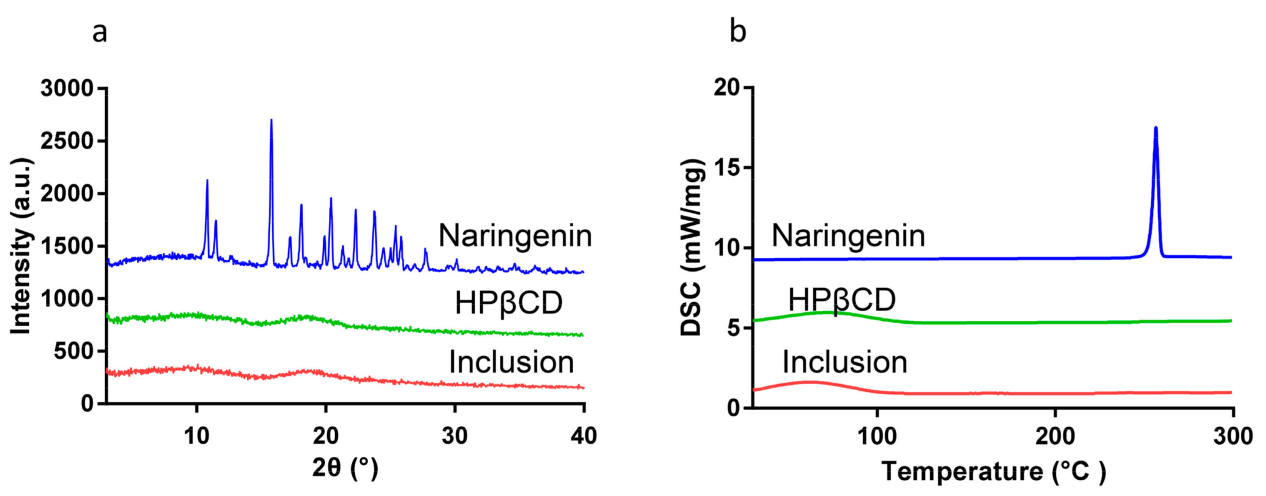

Figure 3. (a) XRD profile and (b) DSC thermogram of naringenin, $\mathrm{HP} \beta C D$, and the inclusion.

\subsection{Differential Scanning Calorimetry (DSC)}

The thermogram of naringenin, $\mathrm{HP} \beta C D$, and their inclusion are shown in Figure $3 \mathrm{~b}$. The DSC curve of naringenin showed an endothermic peak at $256{ }^{\circ} \mathrm{C}$, while the DSC curve of $\mathrm{HP} \beta C D$ contained an endothermic peak at $72{ }^{\circ} \mathrm{C}$. However, in the DSC curve of naringenin-HP $\beta C D$ inclusion, the endothermic peaks at $255{ }^{\circ} \mathrm{C}$ corresponding to naringenin disappeared, and the inclusion exhibited the same endothermic peaks at $72{ }^{\circ} \mathrm{C}$ as the one of $\mathrm{HP} \beta C D$, revealing the formation of the naringenin-HP $\beta C D$ inclusion.

The Fourier transform infrared spectroscopy (FTIR) was also conducted to confirm the formation of naringenin-HP $\beta C D$ inclusion. The results are shown in the Supplementary Materials. 
2.4. Proton Nuclear Magnetic Resonance $\left.{ }^{1} H N M R\right)$ and Two Dimensional Rotating frame Overhauser Effect Spectroscopy (2D-ROESY) Studies

${ }^{1} \mathrm{HNMR}$ technique is an effective tool for predicting the complexation mode of cyclodextrin inclusion by detecting the chemical shift changes of host and guest molecules $(\Delta \delta, \Delta \delta=\delta$ inclusion $\delta$ free) [26]. In the present study, the ${ }^{1} \mathrm{HNMR}$ signals of naringenin, $\mathrm{HP} \beta C D$, and naringenin-HP $\beta C D$ inclusion were compared. The ${ }^{1} \mathrm{HNMR}$ spectra and selected chemical shifts of naringenin and HP $\beta C D$ are shown in Figure 4 and Table 1. As presented in Figure 4, the intensity of signals of naringenin in inclusion was low due to the small percentage in the inclusion. $\mathrm{H}-6$ or $\mathrm{H}-8, \mathrm{H}-2, \mathrm{H}-3^{\prime}$ or $\mathrm{H}-5^{\prime}, \mathrm{H}-2^{\prime}$ or $\mathrm{H}-6^{\prime}$ are protons of ring $\mathrm{A}$ to $\mathrm{C}$ of naringenin; all these protons show chemical shift changes after the formation of inclusion, indicating that the entire naringenin molecule is inserted into the cavity of $\mathrm{HP} \beta C D$. Among the chemical shift changes of these protons, $\mathrm{H}-6$ or $\mathrm{H}-8$, the protons of ring A of naringenin $(\Delta \delta=-0.021)$ exhibit more significant changes than those of $\mathrm{H}-3^{\prime}$ or $\mathrm{H}-5^{\prime}$ and $\mathrm{H}-2^{\prime}$ or $\mathrm{H}-6^{\prime}$ $(\Delta \delta=-0.004)$, the protons of ring $C$ of naringenin. Thus, it can be deduced that ring $A$ of naringenin is located at a deeper position in the cavity of $\mathrm{HP} \beta C D$. In terms of the chemical shift changes of $\mathrm{HP} \beta C D$, it is noteworthy that $\mathrm{H}-3$ and $\mathrm{H}-5$ protons are positioned in the interior of $\mathrm{HP} \beta \mathrm{CD}$, while $\mathrm{H}-3$ protons are near the wide side, H-5 protons are near the narrow side [27]. Therefore, our attention focused on H-3 and H-5 protons. As described in Table 1, the chemical shift changes of H-3 protons were more significant than those of $\mathrm{H}-5$ protons, indicating that the naringenin molecule penetrated into the HP $\beta C D$ cavity from the wide side. Based on these results, together with the 1:1 stoichiometry of naringenin-HP $\beta C D$ inclusion, we proposed that the entire naringenin molecule entered the HP $\beta C D$ cavity from the wide side by orienting ring A of naringenin to the narrow side.

In order to further confirm the complexation mode of naringenin-HP $\beta C D$ inclusion, 2D ROESY spectroscopy was utilized. It is able to reveal the spatial relationships between protons of guest and host molecules of cyclodextrin inclusions. Two protons that are closely located in a space can produce a nuclear Overhauser effect (NOE), presenting as a cross-peak between protons from two molecules in the 2D ROESY spectrum [28]. The ROESY spectra of naringenin-HP $\beta C D$ inclusion (Figure 5) showed cross-peaks between $\mathrm{H}-6$ and $\mathrm{H}-8, \mathrm{H}-2^{\prime}$ or $\mathrm{H}-6^{\prime}$ and $\mathrm{H}-3^{\prime}$ or $\mathrm{H}-5^{\prime}$ protons of naringenin and $\mathrm{H}-3$ and $\mathrm{H}-5$ protons of HP $\beta C D$. Consistent with the observations of ${ }^{1} \mathrm{HNMR}$, the results of 2D ROESY indicated that the entire naringenin molecule was involved in the cavity of $\mathrm{HP} \beta C D$. The possible inclusion mode of naringenin with $\mathrm{HP} \beta C D$ is illustrated in Figure 6.

Table 1. The chemical shift of naringenin and HP $\beta C D$ in free and inclusion state.

\begin{tabular}{ccccc}
\hline \multirow{2}{*}{ Compound } & \multirow{2}{*}{ Proton } & \multicolumn{2}{c}{ Chemical Shift $\delta$ (ppm) } & \multirow{2}{*}{$\Delta \delta$ (ppm) } \\
\cline { 3 - 4 } & & $\delta$ (Free) & $\delta$ (Inclusion) & \\
\hline \multirow{3}{*}{ Naringenin } & 2 & 5.438 & 5.427 & -0.011 \\
& 6 or 8 & 5.878 & 5.857 & -0.021 \\
& $3^{\prime}$ or $5^{\prime}$ & 6.789 & 6.785 & -0.004 \\
& $2^{\prime}$ or $6^{\prime}$ & 7.312 & 7.308 & -0.004 \\
\hline \multirow{2}{*}{ HP $\beta C D$} & H-3 & 3.736 & 3.755 & 0.019 \\
& H-5 & 3.468 & 3.470 & 0.002 \\
\hline
\end{tabular}




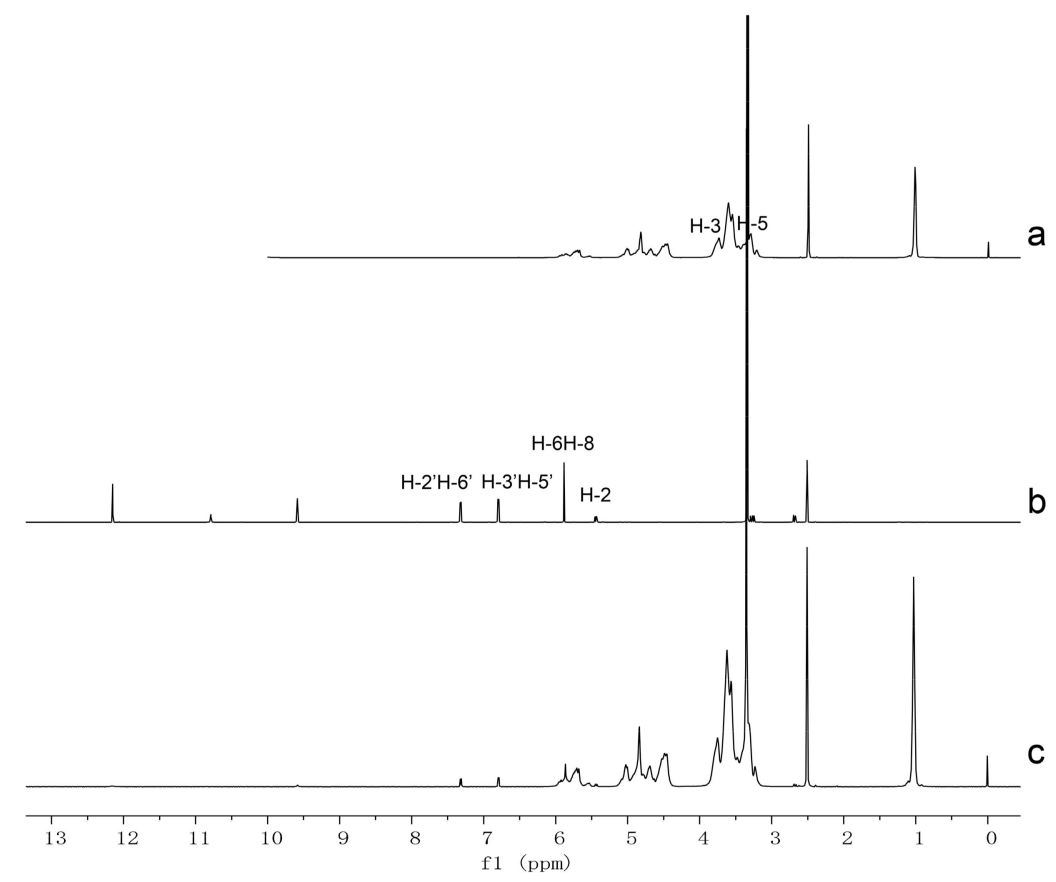

Figure 4. Proton nuclear magnetic resonance $\left({ }^{1} \mathrm{HNMR}\right)$ spectra of $(\mathbf{a}) \mathrm{HP} \beta \mathrm{CD},(\mathbf{b})$ naringenin, and $(\mathbf{c})$ naringenin-HP $\beta C D$ inclusion.

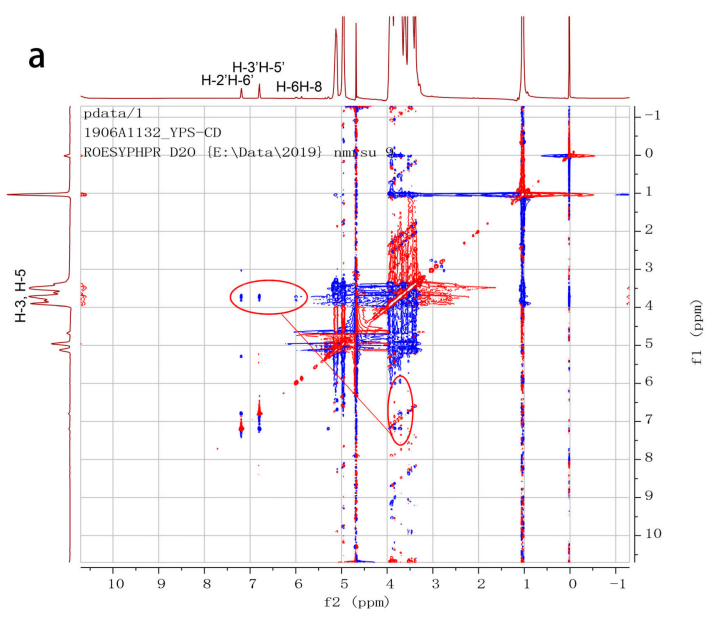

b

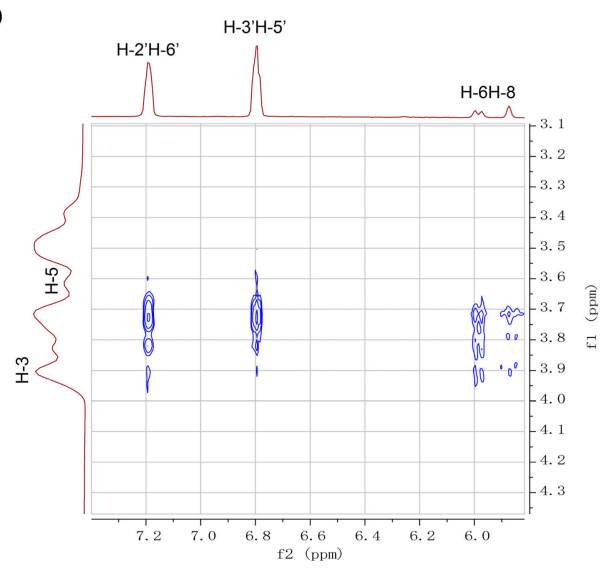

Figure 5. Two-dimensional rotating frame Overhauser effect spectroscopy (2D ROESY) spectrum of (a) naringenin-HP $\beta C D$ inclusion and (b) partial expansion spectrum. 


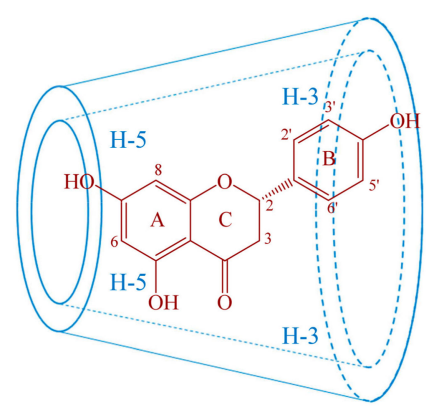

Figure 6. The possible inclusion mode of naringenin with $\mathrm{HP} \beta C D$.

\subsection{Permeation Study}

In order to predict the permeation characteristics of naringenin and its cyclodextrin inclusion, Calu-3 cells were used as a pulmonary epithelial cell model, which can form tightly confluent monolayers with suitable permeability properties for modeling the airway epithelial barrier, resulting in a wide range of applications in permeation studies [29,30]. Furthermore, compared to submersed-liquid culture, Calu-3 cells cultured in air-liquid conditions can provide enhanced ciliogenesis, increased mucus secretion, and tighter junction formation, which is similar to the environment in the respiratory tract [31,32].

The transepithelial electrical resistance (TEER) values of Calu-3 cells are shown in Table 2. After being seeded on the Transwell filter plates, the TEER values of Calu-3 cells increased progressively and reached their plateau at about $580 \Omega \mathrm{cm}^{2}$ for 12-14 days. These results were consistent with other studies, in which the TEER values of Calu-3 cells grown in air-liquid culture were 350-1200 $\Omega$ $\mathrm{cm}^{2}$ [22,33], indicating that the cells already form tight confluent layers for permeation study. There was no significant difference between the TEER values at the beginning $(663 \pm 45 \Omega)$ and at the end of the study $(657 \pm 50 \Omega)$. Thus, the cell layers remained intact during the permeation study.

Table 2. TEER values of Calu-3 cells.

\begin{tabular}{cccccc}
\hline Day & $\mathbf{4}$ & $\mathbf{8}$ & $\mathbf{1 0}$ & $\mathbf{1 2}$ & $\mathbf{1 4}$ \\
\hline $\operatorname{TEER}(\Omega)$ & $212 \pm 25$ & $462 \pm 33$ & $510 \pm 70$ & $576 \pm 30$ & $581 \pm 31$ \\
\hline
\end{tabular}

In the comparison of the permeation characteristics of three different forms of naringenin, naringenin solution showed the highest permeated amount, which was followed by that of inclusion and suspension (Figure 7a). As presented in Table 3, the permeated amount of naringenin solution was about 1.4 and 2.0 times higher than that of inclusion and suspension, respectively. The absorption of a drug is fundamentally dependent on its hydrophilicity and lipophilicity. Octanol-water partition coefficient $(\log P)$, as a parameter of lipophilicity, can be used to predict the affinity of a drug for the cell membranes. It was reported that the $\log \mathrm{P}$ value of naringenin is 2.60 [34], which means that naringenin can easily transport across the cell membranes. However, prior to transporting across the cell membranes, the drug must dissolve in the apical lining fluid of the cells, which is difficult for naringenin due to its poor solubility and dissolution rate. Complexation with HP $\beta$ CD could increase the solubility of naringenin, thus providing a higher drug concentration in the apical lining fluid for permeation, which resulted in an increased permeated amount of naringenin compared with the suspension. The permeated naringenin of the inclusion form was lower than that of the solution form, which could be attributed to the permeability of HP $\beta C D$. As compounds with large molecular weight and polar character, the permeability coefficients (Papp) values of cyclodextrins on Calu-3 cells measured in a previous study were about $7 \times 10^{-8} \mathrm{~cm} / \mathrm{s}$ [35], which were much lower than that of naringenin $\left(8.17 \times 10^{-6}\right)$ calculated in the present study, and the transport mechanisms of cyclodextrins were passive diffusion. The absorptions of cyclodextrins were also proved in vivo; the systemic bioavailabilities of $66-80 \%$ were reported with intratracheal instillation in rabbits [35]. Based 
on the previous in vitro and in vivo studies, it could be speculated that HP $\beta C D$ could be absorbed by pulmonary epithelia cells. Therefore, we deduced that two different forms of naringenin existed in the inclusion system for permeation, one was the free naringenin, and the other one was the complexed naringenin. The complexed form of naringenin with lower Papp value may act as a sustained release system for naringenin. As shown in Figure 7a, while the permeated amount of naringenin solution reached the plateau, the naringenin-HP $\beta C D$ inclusion still showed an increasing trend. Therefore, the application of HP $\beta C D$ promoted the permeation not by directly increasing the permeability of naringenin, but by increasing the drug concentration in the apical lining fluid of cells and acting as a sustained release system for naringenin.

The transport mechanism of naringenin-HP $\beta C D$ inclusion was also evaluated by the concentration-dependence study. As shown in Figure $7 \mathrm{~b}$, the permeated amount of naringenin was proportional to the inclusion concentration, which could be further demonstrated by the linear relation of the flux values of naringenin in this study (Figure 7c), suggesting that at least in the studied concentration range, the transport of naringenin-HP $\beta C D$ inclusion was a diffusion-driven process without the participation of membrane transporters. Similar results were observed previously by complexing other drug with $\mathrm{HP} \beta C D$ [23].
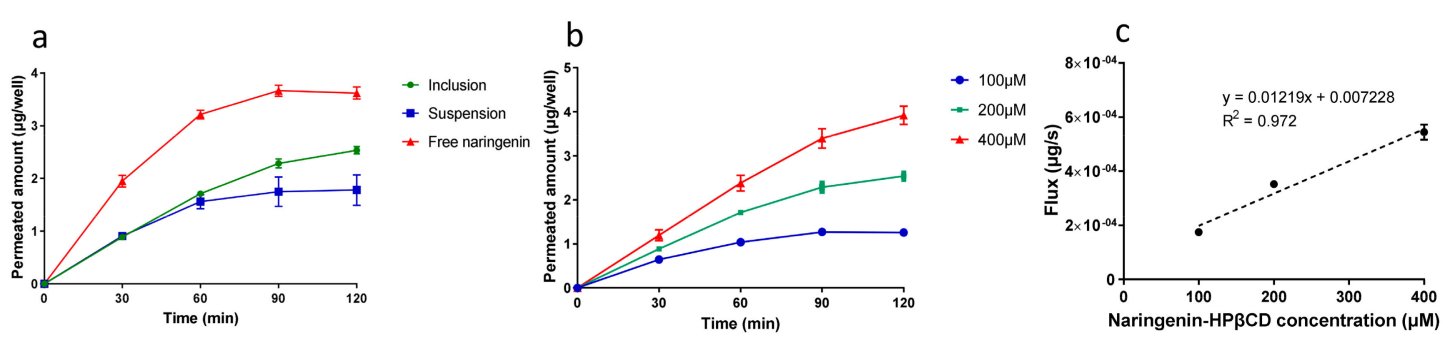

Figure 7. Cumulative permeated amounts of (a) different forms of naringenin and (b) different concentration of naringenin inclusion $(\mathbf{b}),(\mathbf{c})$ naringenin flux of different concentration of naringenin inclusion. (mean $\pm \mathrm{SD}, n=4)$.

Table 3. Permeated amounts and flux values of different forms of naringenin.

\begin{tabular}{ccc}
\hline Form & Permeated Amount $(\mu \mathrm{g} /$ well $)$ & Flux $\left(\boldsymbol{\mu g} / \mathbf{s} \times \mathbf{1 0}^{\mathbf{- 4}}\right)$ \\
\hline Naringenin solution & $3.61 \pm 0.11$ & $5.03 \pm 0.16$ \\
Naringenin inclusion & $2.53 \pm 0.06$ & $3.52 \pm 0.09$ \\
Naringenin suspension & $1.78 \pm 0.30$ & $2.47 \pm 0.40$ \\
\hline
\end{tabular}

\subsection{Pharmacokinetic Studies}

It is reported that naringenin would be metabolized and conjugated during its absorption across the gastrointestinal tract and on circulating through the liver, the major metabolic process is glucuronidation, and most naringenin that exist in plasma are in glucuronidated forms [36]. Previous pharmacokinetic studies demonstrated the low bioavailability of naringenin. After oral administration to rats, the absolute bioavailability of free naringenin was only $3.8 \%$, while it increased to $39.8 \%$ after taking the conjugates into account [37]. The tissue distribution study of oral administration showed that most naringenin concentrated in the gastrointestinal tract, followed by kidney, liver, lung, heart, and spleen. Different from the plasma, most naringenin detected in the lungs was in aglycone form, which may attribute to the increased polarity and molar weight of the conjugates [16]. Therefore, the naringenin concentration in lungs was low after oral administration. In the present work, we studied the plasmatic and pulmonary profiles of naringenin after pulmonary delivery. The concentration-time curves and the pharmacokinetic parameters are present in Figure 8 and Table 4 . With the rapid absorption of pulmonary delivery, the $\mathrm{T}_{\max }$ of intratracheal instillation (i.t.) group was $0.181 \mathrm{~h}$, which was slightly longer than that of the intravenous group (i.v.) (0.083 h). The absolute bioavailability of the intratracheal instillation group was $87 \%$ when the naringenin conjugates were 
taken into account, indicating a remarkable enhancement compared with that of oral administration $(39.8 \%)$ [37]. Consistent with the systematic profile, the $\mathrm{T}_{\max }$ of lung tissue profile was $0.181 \mathrm{~h}$. The $\mathrm{C}_{\max }$ and the area under the concentration-time curve $\mathrm{AUC}_{(0-\mathrm{t})}$ were $302.09 \mathrm{ng} / \mathrm{g}$ and 378.21 $\mathrm{ng} / \mathrm{g}^{*} \mathrm{~h}$, respectively. Compared with the previous tissue distribution study of oral administration of naringenin glucoside at $42 \mathrm{mg} / \mathrm{kg}$ dose [17], in which the $C_{\max }$ and $\mathrm{AUC}_{(0-\mathrm{t})}$ of lung were $54.76 \mathrm{ng} / \mathrm{g}$ and $251.34 \mathrm{ng} / \mathrm{g}^{*} \mathrm{~h}$, pulmonary delivery presented higher $\mathrm{C}_{\max }$ and $\mathrm{AUC}_{(0-\mathrm{t})}$ values with much a lower dosage. Intratracheal instillation can provide prediction of the pharmacokinetic profiles of pulmonary delivery, however, it cannot completely mimic the clinical delivery, in which the inhalation solutions would be deliver as aerosols with nebulizers and inhaled from the nose or mouth. Therefore, further investigations are needed to clearly illustrate the pharmacokinetic performance of pulmonary delivery of inhalation solutions.

Compared with other formulation strategies of naringenin in the literatures, such as self-nanoemulsifying drug delivery system, solid dispersions and nanoparticles, the composition of our formulation is simple with HP $\beta C D$ as the only excipient. HP $\beta C D$ is used extensively as a safe and effective solubilizing excipient in various delivery routes. It was reported that cyclodextrins were introduced to the formulation of naringenin for oral and ocular delivery [12,15]. In our study, the feasibility of preparing a naringenin-HP $\beta C D$ inclusion for pulmonary delivery was evaluated. With the superiority of pulmonary delivery, the absolute bioavailability is more than twice that of oral administration. In addition, while the $\mathrm{T}_{\max }$ of lung tissue in oral naringenin formulation was $0.5 \mathrm{~h} \mathrm{[14]}$, the one of pulmonary delivery was $0.183 \mathrm{~h}$, which is crucial for the treatment of respiratory diseases. The ratio of HP $\beta C D$ used in our formulation was relatively high; therefore, in future study, the preparation and formulation of the naringenin-HP $\beta C D$ inclusion would be optimized to further reduce the amount of $\mathrm{HP} \beta C D$.
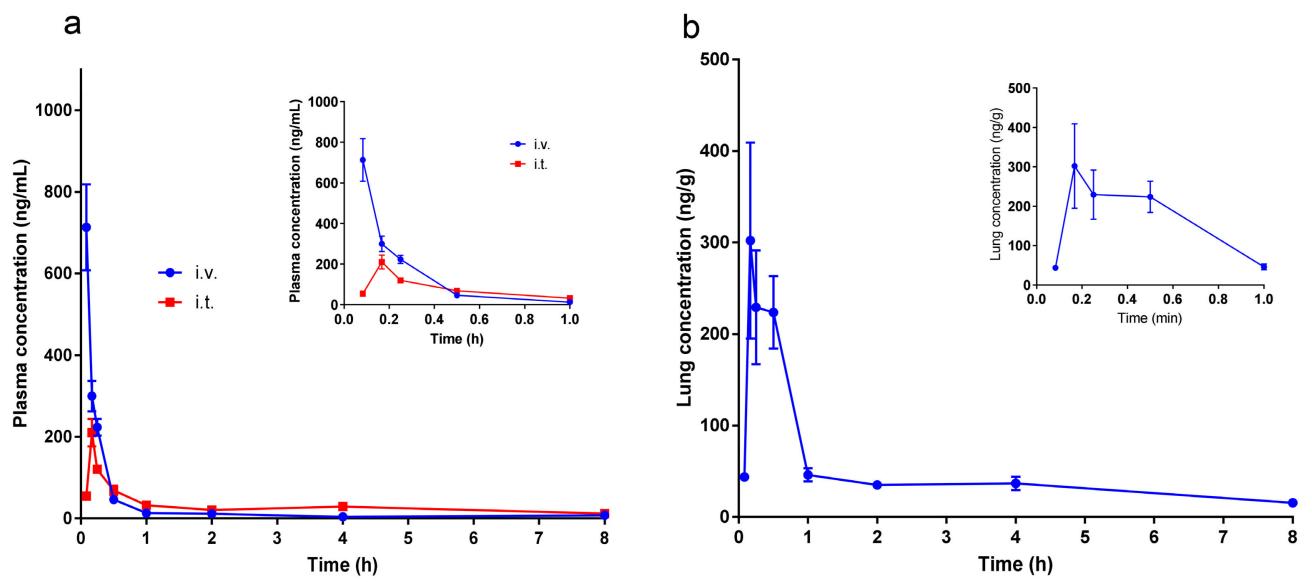

Figure 8. (a) Plasmatic pharmacokinetic profile of naringenin inclusion of i.v. and i.t. administration, inset was the magnification of the profile within $0.083 \sim 1 \mathrm{~h}$; (b) pulmonary pharmacokinetic profile of naringenin inclusion of i.t. administration, inset was the magnification of the profile within $0.083 \sim 1 \mathrm{~h}$ (mean \pm SEM, $n=6$ ). 
Table 4. Plasmatic pharmacokinetic parameter of naringenin inclusion of i.v. and i.t. administration.

\begin{tabular}{|c|c|c|}
\hline Parameter & IV & IT \\
\hline AUC0-t $(\mu \mathrm{g} / \mathrm{L} * \mathrm{~h})$ & $268.20 \pm 85.62$ & $233.60 \pm 37.47$ \\
\hline $\operatorname{AUC}(0-\infty)(\mu \mathrm{g} / \mathrm{L} * \mathrm{~h})$ & $273.00 \pm 84.46$ & $291.15 \pm 77.18$ \\
\hline $\operatorname{Tmax}(\mathrm{h})$ & 0.083 & $0.181 \pm 0.034$ \\
\hline $\mathrm{Cmax}(\mu \mathrm{g} / \mathrm{L})$ & $713.12 \pm 258.564$ & $217.86 \pm 66.35$ \\
\hline$t_{1 / 2}(h)$ & $2.25 \pm 0.90$ & $4.15 \pm 2.13$ \\
\hline Clearance $(\mathrm{L} / \mathrm{h} / \mathrm{kg})$ & $1.59 \pm 0.51$ & $1.46 \pm 0.38$ \\
\hline Bioavailability (\%) & \multicolumn{2}{|c|}{$87^{1}$} \\
\hline
\end{tabular}

${ }^{1}$ The absolute bioavailability of $87 \%$ was calculated by taking the naringenin conjugates into account.

\section{Materials and Methods}

\subsection{Materials}

Naringenin (purity: 95\%) was purchased from Yanhao Biotechnology Co., Ltd. (Xi'an, China). $\mathrm{HP} \beta C D$ (MW 1374) was purchased from Binzhou Zhiyuan Biotechnology Co., Ltd. (Binzhou, Shandong, China). Naringenin, isoquercitrin reference standards, and $\beta$-glucuronidase/sulfatase (Type H-1) were purchased from Sigma-Aldrich (St. Louis, MO, USA). Mass spectrometry (MS) grade methanol and formic acid were purchased from Fisher Scientific (Fair Lawn, NJ, USA). High-performance liquid chromatography (HPLC) grade methanol and ethyl acetate were purchased from Honeywell B\&J (Albany, NY, USA). Water was prepared using a Milli-Q purification system (Millipore, MA, USA)

Dulbecco's modified Eagle's medium/F12 (DMEM/F12), MEM non-essential amino acid (MEM NEAA), and fetal bovine serum (FBS) were purchased from Gibco (Grand Island, NY, USA). Penicillin-streptomycin and Hank's balanced salt solution (HBSS) were purchased from Hyclone (South Logan, UT, USA). Dimethyl sulfoxide (DMSO) was purchased from Sigma-Aldrich (St. Louis, MO, USA).

\subsection{Phase Solubility Study}

An excess amount of naringenin was added to $20 \mathrm{~mL}$ of $\mathrm{HP} \beta C D$ solutions of which the concentration range was from 14.29-114.29 mM. The suspensions were stirred in shaker (MaxQ 6000, Thermo Scientific ${ }^{\mathrm{TM}}$ ) at $25^{\circ} \mathrm{C}$ for $48 \mathrm{~h}$ to reach equilibrium. Naringenin-HP $\beta C D$ inclusion solution was obtained by filtering the suspensions with $0.45 \mu \mathrm{m}$ filter. The naringenin concentration was detected by UV spectroscopy after sample dilution. The maximum absorbance of naringenin is $288 \mathrm{~nm}$, while HP $\beta C D$ shows no absorbance at the same wavelength. Each experiment was carried out in triplicate. The concentration of solubilized naringenin $(\mathrm{mM})$ was plotted against the corresponding concentration of HP $\beta C D(\mathrm{mM})$. The slope and y-intercept (So) of the linear regression was used to calculate the complexation parameter as follows:

$$
\begin{aligned}
& \text { Stability constant, } \mathrm{Ks}=\text { slope/[So } \times(1-\text { slope })] \text {, } \\
& \text { Complexation efficiency, } \mathrm{CE}=\text { slope/( } 1 \text { - slope }) \text {, }
\end{aligned}
$$

\subsection{Preparation of Naringenin-HP $\beta C D$ Inclusion}

According to the results of the phase solubility study, the molar ratio of naringenin to HP $\beta C D$ in saturated condition was 1:5. Considering the stability of the formulation, all naringenin-HP $\beta C D$ solutions used in present study were prepared with double amounts of $\mathrm{HP} \beta C D$, and the molar ratio was 1:10. For the subsequent XRD, DSC, IR, and NMR studies, naringenin and HP $\beta C D$ were added to water and shaken in a flask at room temperature for $12 \mathrm{~h}$, then the inclusion powder was accessed by lyophilization of the filtered naringenin-HP $\beta C D$ solution. For permeation and pharmacokinetic 
studies, corresponding concentrations of naringenin-HP $\beta C D$ solutions were prepared with the same method, while the solvents were replaced with HBSS and saline, respectively.

\section{4. $X R D$}

$X R D$ experiments of naringenin, $\mathrm{HP} \beta C D$, and naringenin- $\mathrm{HP} \beta C D$ inclusion were performed on an X-ray diffractometer (Empyrean, PANalytical Corporation, Almelo, Netherlands). A copper anode providing $\mathrm{CuK} \alpha$ radiation at $40 \mathrm{kV}$ and $40 \mathrm{~mA}$ was adopted. The recorded range of $2 \theta$ was from $3^{\circ}$ to $40^{\circ}$.

\subsection{DSC}

DSC experiments of naringenin, $\mathrm{HP} \beta C \mathrm{C}$, and naringenin-HP $\beta C D$ inclusion were performed on DSC-204 (Netzsch, Germany) under $70 \mathrm{~mL} / \mathrm{min}$ of nitrogen flow. Signals were recorded within $30-300{ }^{\circ} \mathrm{C}$ at a heating rate of $10^{\circ} \mathrm{C} / \mathrm{min}$.

\subsection{HNMR and $2 D$ ROESY}

${ }^{1} \mathrm{HNMR}$ and 2D ROESY experiments were performed on a Bruker AVANCE III 600 spectrometer (Billerica, MA, USA). 2D ROESY spectrum was recorded with a mixing time of $300 \mathrm{~ms}$, and 16 scans were collected for each of the 256 experiments. In all experiments, the probe temperature was maintained at $298 \mathrm{~K}$ and standard $5 \mathrm{~mm}$ NMR tubes were used. In ${ }^{1} \mathrm{HNMR}$ experiments, all samples were dissolved in DMSO- $d_{6}$, while in the 2D ROESY experiment, naringenin-HP $\beta C D$ inclusion was dissolved in $\mathrm{D}_{2} \mathrm{O}$.

\subsection{Permeation Study of Naringenin- HP $\beta C D$ Inclusion}

\subsubsection{Cell Culture}

Calu-3 cells were gifts from Dr. Wing-Hung Ko at The Chinese University of Hong Kong, Hong Kong, China. The cells were cultured with DMEM/F12 supplemented with $10 \%$ fetal bovine serum, $1 \%$ MEM NEAA, and $100 \mathrm{U} / \mathrm{mL}$ penicillin-streptomycin solution at $37^{\circ} \mathrm{C}$ in a humidified atmosphere of $5 \%(v / v) \mathrm{CO}_{2}$. The cultured medium was changed every 2-3 days and the cells were passaged weekly before seeding. To obtain confluent cell monolayers, Calu-3 cells were seeded on Transwell ${ }^{\circledR}$ filter plate (12 mm diameter inserts, $0.4 \mu \mathrm{m}$ pore size, Corning, NY, USA) at a density of $5 \times 10^{5}$ cells/well with $500 \mu \mathrm{L}$ medium in the apical chamber and $1500 \mu \mathrm{L}$ medium in the basolateral chamber. After 2 days, the apical medium was removed to create an air-liquid interface culture, and the medium of basolateral chamber was changed to $1000 \mu \mathrm{L}$. The medium was changed every 2 days.

\subsubsection{TEER Values Measurement}

The TEER values were measured every $2-4$ days with Millicell ${ }^{\circledR}$-ERS-2 (Merck Milipore, Billerica, MA, USA). When measuring TEER values, 500 and $1500 \mu \mathrm{L}$ medium were added to the apical and basolateral chamber, respectively. Prior to the measurement, the cells were equilibrated for $30 \mathrm{~min}$ in the incubator. After 12-14 days, the cell layers with stable TEER values ( $>500 \Omega$ ) were ready for the permeation study. To monitor the integrity of the cell layer, TEER values were also determined before and after the permeation study by replacing the cultured medium with HBSS.

\subsubsection{Permeation Study}

To access the influence of HP $\beta C D$ on the permeation of naringenin, the permeation characteristics of three different forms of naringenin (solution, suspension, and naringenin-HP $\beta C D$ inclusion) were evaluated at the same dose $(200 \mu \mathrm{M})$. Naringenin solution was prepared by dissolving naringenin in DMSO due to its poor solubility, and then the stock solution was diluted with HBSS to reach the final concentration (the concentration of DMSO in this solution was $0.1 \%(v / v)$ ). Naringenin suspension was prepared by adding the corresponding amount of naringenin powder in HBSS, 
and in order to evenly disperse the naringenin powder, the suspension was ultrasound for $1 \mathrm{~h}$. For the concentration-dependent study, 100, 200, and $400 \mu \mathrm{M}$ naringenin-HP $\beta C D$ inclusions were prepared according to the method mentioned in Section 2.3. Both the concentrations of naringenin and naringenin-HP $\beta C D$ inclusion applied in this study exhibited no cytotoxicity with CellTiter $96^{\circledR}$ AQueous One Solution Cell Proliferation Assay (MTS) in preliminary studies. Before the permeation study, the cell layers were washed twice by $500 \mu \mathrm{L}$ HBSS, then the apical chamber and basolateral chamber of each well were filled with $500 \mu \mathrm{L}$ and $1500 \mu \mathrm{L}$ HBSS, respectively, for TEER determination. After that, the HBSS in the apical chamber was discarded, and the volume of basolateral chamber was changed to $1000 \mu \mathrm{L}$, then $150 \mu \mathrm{L}$ drugs were pipetted onto the cell layers. The transwell plates were agitated by using an orbital shaker at $200 \mathrm{rpm}$ stirring rate and at $37^{\circ} \mathrm{C}$ during the entire exposure time. Then, $120 \mu \mathrm{L}$ samples from the basolateral chamber were taken at 0, 30, 60, 90, and 120 min and replaced with pre-warmed HBSS buffer; the naringenin concentration of sample was assayed by HPLC. TEER values were measured after the permeation study to investigate the influence on cell layers.

Papp value was calculated according to the following equation, where $\mathrm{dQ} / \mathrm{dt}$ is the flux across the cell monolayer $(\mu \mathrm{g} / \mathrm{s}), \mathrm{A}$ is the surface of the monolayer $\left(\mathrm{cm}^{2}\right)$, and $\mathrm{C}$ is the initial concentration in the apical chamber $(\mu \mathrm{g} / \mathrm{mL})$

$$
\mathrm{P}_{\mathrm{app}}=\mathrm{dQ} /(\mathrm{dt} \times \mathrm{A} \times \mathrm{C}),
$$

\subsubsection{HPLC Assay}

The concentration of naringenin was quantified by Ultimate 3000 DGLG HPLC (Dionex, Waltham, MA, USA) equipped with LPG-3400SD pump, WPS-3000SL sampler, TCC3000-RS column oven, and photo-diode-array-detector (DAD). The analytical column used was Elite Hypersil ODS2 $(4.6 \times 250 \mathrm{~mm})$. The mobile phase consisted of methanol and water in a 55:45 ratio. The flow rate was $1 \mathrm{~mL} / \mathrm{min}$, and the column temperature was $25^{\circ} \mathrm{C}$. The maximum absorbance of naringenin was $288 \mathrm{~nm}$. Linearity was proven in the range of 0.5 to $20 \mu \mathrm{g} / \mathrm{mL}$. The validation parameters of the methodology of HPLC assay is provided in the Supplementary Materials.

\subsection{Pharmacokinetic Study}

\subsubsection{Animals}

Male and female Sprague-Dawley (SD) rats weighing 180-220 g (9 weeks-old) were supplied by Guangdong Medical Laboratory Animal Center (Guangzhou, China). Animals were acclimated at least 3 days before the pharmacokinetic study to environment with $20-25^{\circ} \mathrm{C}$ and $55 \pm 15 \%$ humidity, $12 \mathrm{~h}$ light/dark cycle was applied. Food and water were provided ad libitum. The animals were fasted overnight with free access to water before the experiment. All experimental procedures complied with the National Institutes of Health Guide for the Care and Use of Laboratory Animals (NIH Publications No. 8023, revised 1978), and were approved by the Animal Ethics Committee of the School of Life Sciences in Sun Yat-sen University (approval number: 180613 and 180614, date: 2018/06/08).

\subsubsection{Administration Protocol}

For the intratracheal instillation study, $48 \mathrm{SD}$ rats (half male and half female) were randomly divided into 8 groups corresponding to the predetermined sample collection time points $(0.083,0.167$, $0.25,0.5,1,2,4,8 \mathrm{~h})$. Animals were intraperitoneally injected with $10 \%$ chloral hydrate $(w / v, \mathrm{~g} / \mathrm{mL})$ for anesthesia, and then a volume of $50 \mu \mathrm{L} / 100 \mathrm{~g}$ of naringenin-HP $\beta C D$ inclusion was given to the rats. The dose was $400 \mu \mathrm{g} / \mathrm{kg}$. After intratracheal instillation administration, the whole blood was collected from the retro orbital at the aforementioned time points. Animals were sacrificed by cervical dislocation, the lungs were excised by surgical resection, and the visible bronchi were removed. For intravenous administration, $6 \mathrm{SD}$ rats (half male and half female) were randomly selected and administrated with the same dose intravenously. Blood samples were collected at the same time points as mentioned before. Plasma samples were obtained by immediate centrifugation at $4000 \mathrm{r} / \mathrm{min}$ centrifugation 
for $10 \mathrm{~min}$ at $4{ }^{\circ} \mathrm{C}$. Both plasma samples and lung tissues were stored at $-80{ }^{\circ} \mathrm{C}$ before assay. The samples of pharmacokinetic study were quantified by liquid chromatography-triple quadrupole mass spectrometry (LC-MS/MS, Agilent Technology, Santa Clara, CA, USA). The sample preparation and quantitative methods are referred to in our previous studies $[17,38]$.

\section{Conclusions}

This study showed that complexation with $\mathrm{HP} \beta C D$ was able to increase the solubility of naringenin effectively. ${ }^{1} \mathrm{HNMR}$ and 2D ROESY studies illustrated that the entire naringenin molecule was involved in the cavity of HP $\beta C D$ to form a 1:1 inclusion. The application of HP $\beta C D$ could not only increase the naringenin concentration in the epithelium-lining fluid (ELF) of pulmonary epithelial cells, but also act as a sustained release system. Furthermore, pharmacokinetic study showed that pulmonary delivery of naringenin-HP $\beta C D$ inclusion provided rapid response and higher local concentration of naringenin, which is critical for improving the therapeutic effects for respiratory diseases.

Supplementary Materials: The supplementary materials are available online.

Author Contributions: M.G., Y.W., and W.S. conceived and designed the study. M.G., R.S., Y.Z., and X.Z. analyzed the data and wrote the manuscript. M.G., R.S., Y.Z., X.Z., and W.F. conducted the experiment. All authors have read and agreed to the published version of the manuscript.

Funding: This research was supported by the Applied Science and Technology R\&D Special Fund Project of Guangdong Province (No. 2015B020234004).

Conflicts of Interest: The authors declare no conflicts of interest.

\section{References}

1. Khan, A.W.; Kotta, S.; Ansari, S.H.; Sharma, R.K.; Ali, J. Self-nanoemulsifying drug delivery system (SNEDDS) of the poorly water-soluble grapefruit flavonoid Naringenin: Design, characterization, in vitro and in vivo evaluation. Drug Delivery 2015, 22, 552-561. [CrossRef] [PubMed]

2. Wu, C.; Ji, P.; Yu, T.; Liu, Y.; Jiang, J.; Xu, J.; Zhao, Y.; Hao, Y.; Qiu, Y.; Zhao, W. Naringenin-loaded solid lipid nanoparticles: Preparation, controlled delivery, cellular uptake, and pulmonary pharmacokinetics. Drug Des. Dev. Ther. 2016, 10, 911. [CrossRef] [PubMed]

3. Lin, B.Q.; Li, P.B.; Wang, Y.G.; Peng, W.; Wu, Z.; Su, W.W.; Ji, H. The expectorant activity of naringenin. Pulm. Pharmacol. Ther. 2008, 21, 259-263. [CrossRef] [PubMed]

4. Liu, Y.; Wu, H.; Nie, Y.C.; Chen, J.L.; Su, W.W.; Li, P.B. Naringin attenuates acute lung injury in LPS-treated mice by inhibiting NF-kappaB pathway. Int. Immunopharmacol. 2011, 11, 1606-1612. [CrossRef] [PubMed]

5. Luo, Y.L.; Zhang, C.C.; Li, P.B.; Nie, Y.C.; Wu, H.; Shen, J.G.; Su, W.W. Naringin attenuates enhanced cough, airway hyperresponsiveness and airway inflammation in a guinea pig model of chronic bronchitis induced by cigarette smoke. Int. Immunopharmacol. 2012, 13, 301-307. [CrossRef]

6. Nie, Y.C.; Wu, H.; Li, P.B.; Luo, Y.L.; Long, K.; Xie, L.M.; Shen, J.G.; Su, W.W. Anti-inflammatory effects of naringin in chronic pulmonary neutrophilic inflammation in cigarette smoke-exposed rats. J. Med. Food 2012, 15, 894-900. [CrossRef]

7. Nie, Y.C.; Wu, H.; Li, P.B.; Xie, L.M.; Luo, Y.L.; Shen, J.G.; Su, W.W. Naringin attenuates EGF-induced MUC5AC secretion in A549 cells by suppressing the cooperative activities of MAPKs-AP-1 and IKKs-IkappaB-NF-kappaB signaling pathways. Eur. J. Pharmacol. 2012, 690, 207-213. [CrossRef]

8. Jiao, H.Y.; Su, W.W.; Li, P.B.; Liao, Y.; Zhou, Q.; Zhu, N.; He, L.L. Therapeutic effects of naringin in a guinea pig model of ovalbumin-induced cough-variant asthma. Pulm. Pharmacol. Ther. 2015, 33, 59-65. [CrossRef]

9. Shi, R.; Xiao, Z.T.; Zheng, Y.J.; Zhang, Y.L.; Xu, J.W.; Huang, J.H.; Zhou, W.L.; Li, P.B.; Su, W.W. Naringenin Regulates CFTR Activation and Expression in Airway Epithelial Cells. Cell. Physiol. Biochem. 2017, 44, 1146-1160. [CrossRef]

10. Shi, R.; Su, W.W.; Zhu, Z.T.; Guan, M.Y.; Cheng, K.L.; Fan, W.Y; Wei, G.Y.; Li, P.B.; Yang, Z.Y.; Yao, H.L. Regulation effects of naringin on diesel particulate matter-induced abnormal airway surface liquid secretion. Phytomedicine 2019, 63, 153004. [CrossRef] 
11. Shi, R.; Xu, J.W.; Xiao, Z.T.; Chen, R.F.; Zhang, Y.L.; Lin, J.B.; Cheng, K.L.; Wei, G.Y.; Li, P.B.; Zhou, W.L.; et al. Naringin and Naringenin Relax Rat Tracheal Smooth by Regulating BKCa Activation. J. Med. Food 2019. [CrossRef] [PubMed]

12. Shulman, M.; Cohen, M.; Soto-Gutierrez, A.; Yagi, H.; Wang, H.; Goldwasser, J.; Lee-Parsons, C.W.; Benny-Ratsaby, O.; Yarmush, M.L.; Nahmias, Y. Enhancement of naringenin bioavailability by complexation with hydroxypropyl- $\beta$-cyclodextrin. [corrected]. PLoS ONE 2011, 6, e18033. [CrossRef] [PubMed]

13. Khan, A.W.; Kotta, S.; Ansari, S.H.; Sharma, R.K.; Ali, J. Enhanced dissolution and bioavailability of grapefruit flavonoid Naringenin by solid dispersion utilizing fourth generation carrier. Drug Dev. Ind. Pharm. 2015, 41, 772-779. [CrossRef] [PubMed]

14. Wang, Y.; Wang, S.; Firempong, C.K.; Zhang, H.; Wang, M.; Zhang, Y.; Zhu, Y.; Yu, J.; Xu, X. Enhanced Solubility and Bioavailability of Naringenin via Liposomal Nanoformulation: Preparation and In Vitro and In Vivo Evaluations. AAPS PharmSciTech 2017, 18, 586-594. [CrossRef] [PubMed]

15. Zhang, P.; Liu, X.; Hu, W.; Bai, Y.; Zhang, L. Preparation and evaluation of naringenin-loaded sulfobutylether-beta-cyclodextrin/chitosan nanoparticles for ocular drug delivery. Carbohydr. Polym. 2016, 149, 224-230. [CrossRef]

16. El Mohsen, M.A.; Marks, J.; Kuhnle, G.; Rice-Evans, C.; Moore, K.; Gibson, G.; Debnam, E.; Srai, S.K. The differential tissue distribution of the citrus flavanone naringenin following gastric instillation. Free Radic. Res. 2004, 38, 1329-1340. [CrossRef]

17. Zou, W.; Yang, C.; Liu, M.; Su, W. Tissue distribution study of naringin in rats by liquid chromatography-tandem mass spectrometry. Arzneimittel-Forschung 2012, 62, 181-186. [CrossRef]

18. Zeng, X.; Su, W.; Zheng, Y.; He, Y.; He, Y.; Rao, H.; Peng, W.; Yao, H. Pharmacokinetics, Tissue Distribution, Metabolism, and Excretion of Naringin in Aged Rats. Front. Pharmacol. 2019, 10, 34. [CrossRef]

19. Pilcer, G.; Amighi, K. Formulation strategy and use of excipients in pulmonary drug delivery. Int. J. Pharm. 2010, 392, 1-19. [CrossRef]

20. Bur, M.; Huwer, H.; Muys, L.; Lehr, C.-M. Drug Transport Across Pulmonary Epithelial Cell Monolayers: Effects of Particle Size, Apical Liquid Volume, and Deposition Technique. J. Aerosol Med. Pulm. Drug Deliv. 2010, 23, 119-127. [CrossRef]

21. Brewster, M.E.; Loftsson, T. Cyclodextrins as pharmaceutical solubilizers. Adv. Drug Deliv. Rev. 2007, 59, 645-666. [CrossRef] [PubMed]

22. Evrard, B.; Bertholet, P.; Gueders, M.; Flament, M.P.; Piel, G.; Delattre, L.; Gayot, A.; Leterme, P.; Foidart, J.M.; Cataldo, D. Cyclodextrins as a potential carrier in drug nebulization. J. Controll. Release 2004, 96, 403-410. [CrossRef] [PubMed]

23. Tewes, F.; Brillault, J.; Couet, W.; Olivier, J.-C. Formulation of rifampicin-cyclodextrin complexes for lung nebulization. J. Controll. Release 2008, 129, 93-99. [CrossRef] [PubMed]

24. Thi, T.H.; Azaroual, N.; Flament, M.P. Characterization and in vitro evaluation of the formoterol/cyclodextrin complex for pulmonary administration by nebulization. Eur. J. Pharm. Biopharm. 2009, 72, 214-218. [CrossRef] [PubMed]

25. Mohtar, N.; Taylor, K.M.; Sheikh, K.; Somavarapu, S. Design and development of dry powder sulfobutylether-beta-cyclodextrin complex for pulmonary delivery of fisetin. Eur. J. Pharm. Biopharm. 2017, 113, 1-10. [CrossRef] [PubMed]

26. He, J.; Zheng, Z.P.; Zhu, Q.; Guo, F.; Chen, J. Encapsulation Mechanism of Oxyresveratrol by $\beta$-Cyclodextrin and Hydroxypropyl- $\beta$-Cyclodextrin and Computational Analysis. Molecules 2017, 22, 1801. [CrossRef]

27. Huang, Z.; Xu, R.; Ge, X.; Cheng, J. Complexation of capsaicin with hydroxypropyl-beta-cyclodextrin and its analytical application. Spectrochim. Acta Part A Mol. Biomol. Spectrosc. 2019, 223, 117278. [CrossRef]

28. Adhikari, S.; Daftardar, S.; Fratev, F.; Rivera, M.; Sirimulla, S.; Alexander, K.; Boddu, S.H.S. Elucidation of the orientation of selected drugs with 2-hydroxylpropyl-beta-cyclodextrin using 2D-NMR spectroscopy and molecular modeling. Int. J. Pharm. 2018, 545, 357-365. [CrossRef]

29. Asai, A.; Okuda, T.; Sonoda, E.; Yamauchi, T.; Kato, S.; Okamoto, H. Drug Permeation Characterization of Inhaled Dry Powder Formulations in Air-Liquid Interfaced Cell Layer Using an Improved, Simple Apparatus for Dispersion. Pharma. Res. 2016, 33, 487-497. [CrossRef]

30. Bur, M.; Rothen-Rutishauser, B.; Huwer, H.; Lehr, C.M. A novel cell compatible impingement system to study in vitro drug absorption from dry powder aerosol formulations. Eur. J. Pharm. Biopharm. 2009, 72, 350-357. [CrossRef] 
31. Ong, H.X.; Traini, D.; Young, P.M. Pharmaceutical applications of the Calu-3 lung epithelia cell line. Expert Opin. Drug Deliv. 2013, 10, 1287-1302. [CrossRef] [PubMed]

32. Sakagami, M. In vivo, in vitro and ex vivo models to assess pulmonary absorption and disposition of inhaled therapeutics for systemic delivery. Adv. Drug Deliv. Rev. 2006, 58, 1030-1060. [CrossRef] [PubMed]

33. Meindl, C.; Stranzinger, S.; Dzidic, N.; Salar-Behzadi, S.; Mohr, S.; Zimmer, A.; Frohlich, E. Permeation of Therapeutic Drugs in Different Formulations across the Airway Epithelium In Vitro. PLoS ONE 2015, 10, e0135690. [CrossRef] [PubMed]

34. Rothwell, J.A.; Day, A.J.; Morgan, M.R.A. Experimental Determination of Octanol-Water Partition Coefficients of Quercetin and Related Flavonoids. J. Agric. Food Chem. 2005, 53, 4355-4360. [CrossRef]

35. Matilainen, L.; Toropainen, T.; Vihola, H.; Hirvonen, J.; Jarvinen, T.; Jarho, P.; Jarvinen, K. In vitro toxicity and permeation of cyclodextrins in Calu-3 cells. J. Controll. Release 2008, 126, 10-16. [CrossRef]

36. Ma, Y.; Li, P.; Chen, D.; Fang, T.; Li, H.; Su, W. LC/MS/MS quantitation assay for pharmacokinetics of naringenin and double peaks phenomenon in rats plasma. Int. J. Pharm. 2006, 307, 292-299. [CrossRef]

37. Fang, T.Z. Studies on Pharmacodynamics and Pharmacokinetics of Naringenin. Ph.D Thesis, Sun Yat-Sen University, Guangzhou, China, 2005.

38. Zeng, X.; Su, W.; Liu, H.; Zheng, Y.; Chen, T.; Zhang, W.; Yan, Z.; Bai, Y.; Yao, H. Simultaneous determination of rosuvastatin, naringin and naringenin in rat plasma by RRLC-MS/MS and its application to a pharmacokinetic drug interaction study. J. Chromatogr. Sci. 2018, 56, 611-618. [CrossRef]

Sample Availability: Samples of the compounds are not available from the authors.

(C) 2020 by the authors. Licensee MDPI, Basel, Switzerland. This article is an open access article distributed under the terms and conditions of the Creative Commons Attribution (CC BY) license (http://creativecommons.org/licenses/by/4.0/). 